\title{
POEMS Syndrome Diagnosis in a Patient with Mixed Polyneuropathy: Case Report
}

\section{Maria Isabel Ocampo-Navia', María Andrea Negret Noreña ${ }^{2}$, Luis Rafael Chaparro Santos ${ }^{3}$, José Ricardo Morera Afanador ${ }^{3}$, Ricardo Andrés Quintero Farías ${ }^{3}$, José Luis Bustos Sánchez ${ }^{4}$}

${ }^{1}$ Department of Neurosurgery, Hospital Universitario San Ignacio, Pontificia Universidad Javeriana, Bogotá, Colombia;

${ }^{2}$ Department of Internal Medicine, Hospital Universitario San Ignacio, Pontificia Universidad Javeriana, Bogotá, Colombia;

${ }^{3}$ Department of Internal Medicine, Hospital Universitario San Rafael de Tunja, Boyacá, Colombia;

${ }^{4}$ Department of Neuroscience, Hospital Universitario San Rafael de Tunja, Boyacá, Colombia

Received July 30, 2020; Accepted February 16, 2022.

Key words: Paraproteinemia - POEMS syndrome - Plasma cells - Plasmocytoma Polyneuropathy

Abstract: POEMS syndrome is a rare condition of paraneoplasic origin characterized by the presence of a sensorimotor polyneuropathy associated with the presence of a proliferative disorder of plasmatic monoclonal cells and overproduction of vascular endothelial growth factor. The acronym "POEMS" represents multisystem findings including polyneuropathy, organomegaly, endocrinopathy, monoclonal plasma cell disorder and skin changes; nevertheless, clinical presentation is heterogeneous. We describe a clinical case, the diagnostic and therapeutic approach in a patient with sensorimotor polyneuropathy in whom POEMS syndrome was diagnosed; to understand this pathology, its clinical and paraclinical manifestations in order to make a diagnosis or to avoid a delayed one and to provide an adequate treatment.

Mailing Address: Maria Isabel Ocampo-Navia, MD., Department of Neurosurgery, Pontificia Universidad Javeriana, Cra. 7\#40-62, $6^{\text {th }}$ floor, Bogotá 111017, Colombia; e-mail: maria_ocampo@javeriana.edu.co 


\section{Introduction}

POEMS syndrome (Polyneuropathy, Organomegaly, Endocrinopathy, Monoclonal protein, Skin changes) is a rare disease, usually related to a paraneoplastic etiology, characterized by the presence of a monoclonal plasma cell disorder, peripheral neuropathy, and increased levels of serum vascular endothelial growth factor (VEGF) (Plaza et al., 2016; Keddie et al., 2018). The acronym "POEMS" references the most frequent symptoms including: Polyneuropathy, Organomegaly, Endocrinopathy, Monoclonal protein, and specific Skin changes (Plaza et al., 2016; Keddie et al., 2018). Nonetheless, clinical presentation varies greatly in each individual case, and may not present all the criteria. Suichi et al. (2019) estimated a prevalence of 0.3 for 100,000 people, however due to the rarity of said entity, this usually implies a delayed, or even subdiagnosis.

Given that POEMS syndrome is an incapacitating condition, related to high morbidity if not treated early, an opportune diagnosis is key to a more favourable prognosis and adequate lifestyle for these patients. More aggressive treatment options have been used since 2000, including high doses of chemotherapy along with autologous stem cell transplant, immunomodulators, and proteasome inhibitors (Kuwabara et al., 2012; Dispenzieri, 2017; Suichi et al., 2019). The latest evidence establishes that monoclonal antibodies against VEGF are harmful and can lead to death. This suggests that although a useful biomarker in the diagnostic stage, VEGFs pathophysiological role is poorly understood.

This syndrome is unfortunately rarely considered as a differential diagnosis among patients presenting with chronic polyneuropathy without any other related symptoms due to a generalized insufficient knowledge about said condition. This is why a better diagnostic approach plays a fundamental role in avoiding unnecessary studies and can lead to an early diagnostic approach. The objective of this article is to describe a clinical case, along with its diagnostic and therapeutic process, in a patient with mixed polyneuropathy ultimately diagnosed with POEMS syndrome.

\section{Case report}

A 47-year-old man, with a history of acute myocardial infarction with reduced left ventricular ejection fraction, who presents with 6 months of progressive distal muscle weakness that limits functionality, along with paresthesias in all four extremities, and significant weight loss. During the physical examination, generalized areflexia and hypertrophy of both lower limbs are evident.

The electromyography and nerve conduction showed a severe, predominantly demyelinating, polyneuropathy that affected both the motor and sensitive nerves in all four extremities, with a few signs of active denervation.

Other etiologies were ruled out, including deficiencies, metabolic causes, autoimmune and paraneoplastic causes (Table 1). A tomographic search for neoplastic lesions concluded mild diffuse hepatosplenomegaly and ascites. The 
Table 1 - Patient laboratory results

\begin{tabular}{llc}
\hline & Laboratory tests & Value \\
\hline \multirow{3}{*}{ Blood chemistry } & hemoglobine & $10 \mathrm{~g} / \mathrm{dl}$ \\
panel & hematocrite & $30 \%$ \\
& leucocytes & 11,000 \\
& platelets & 332,000 \\
& glucose & $88 \mathrm{mg} / \mathrm{dl}$ \\
\hline \multirow{3}{*}{ Endocrine tests } & TSH & $3.15 \mathrm{mUl} / \mathrm{l}(0.27-4.2)$ \\
& cortisol AM & $10 \mathrm{ug} / \mathrm{dl}(100-140 \mathrm{mmol} / \mathrm{l})$ \\
& ACTH & $515 \mathrm{pg} / \mathrm{ml}(6-76 \mathrm{pg} / \mathrm{ml})$ \\
Metabolic tests & proteins & $6 \mathrm{~g} / \mathrm{dl}$ \\
& albumin & $3 \mathrm{~g} / \mathrm{dl}$ \\
& B12 vitamine & $653 \mathrm{pg} / \mathrm{ml}$ \\
Autoimmune & folic acid & $15 \mathrm{ng} / \mathrm{ml}$ \\
tests & ANAS & $1: 80 \mathrm{diluciones}$ \\
& PANCAS and cANCAS & negative \\
& ENAS (Ro, Sm, La, Rnp) & negative \\
& lupus anticoagulant & negative \\
\hline
\end{tabular}

TSH - thyroid-stimulating hormone; ACTH - adrenocorticotropic hormone

patient was sent home with an unsure diagnosis of a chronic, inflammatory demyelinating polyneuropathy to be treated with corticoids.

Ten months later, the patient returns with worsening paraparesis and dysesthesias, along with an exacerbation of his neurological deficit over the last 20 days, accompanied by edema of both legs (Figure 1). During the physical examination, the patient presents unresponsive hypotension, jugular engorgement, leukonychia, ascites and pitting edema of the lower limbs. Neurological findings include hypotrophy of all four extremities, strength 3/5 in upper limbs and $2 / 5$ in lower limbs, generalized areflexia and distal multimodal hypoesthesia in lower limbs.

Considering a possible chronic polyneuropathy of unknown origin with unclear multisystemic findings, further studies were required. Due to sustained hypotension in spite of vasopressors, endocrine tests were performed which confirmed adrenal insufficiency secondary to low cortisol levels and high ACTH (adrenocorticotropic hormone) levels (Table 1). A new thoracoabdominal computed tomography (CT) showed increased hepatosplenomegaly (Figure 1).

A lumbar puncture reported an albumin-cytological dissociation which led to a sural nerve biopsy that ultimately reported an inflammatory demyelinating mixed axonal neuropathy, in addition to a serum protein electrophoresis that showed slightly elevated levels of beta-1, beta-2, and gamma. Given these findings, serum immunofixation was done which showed IgA lambda monoclonal gammopathy. 

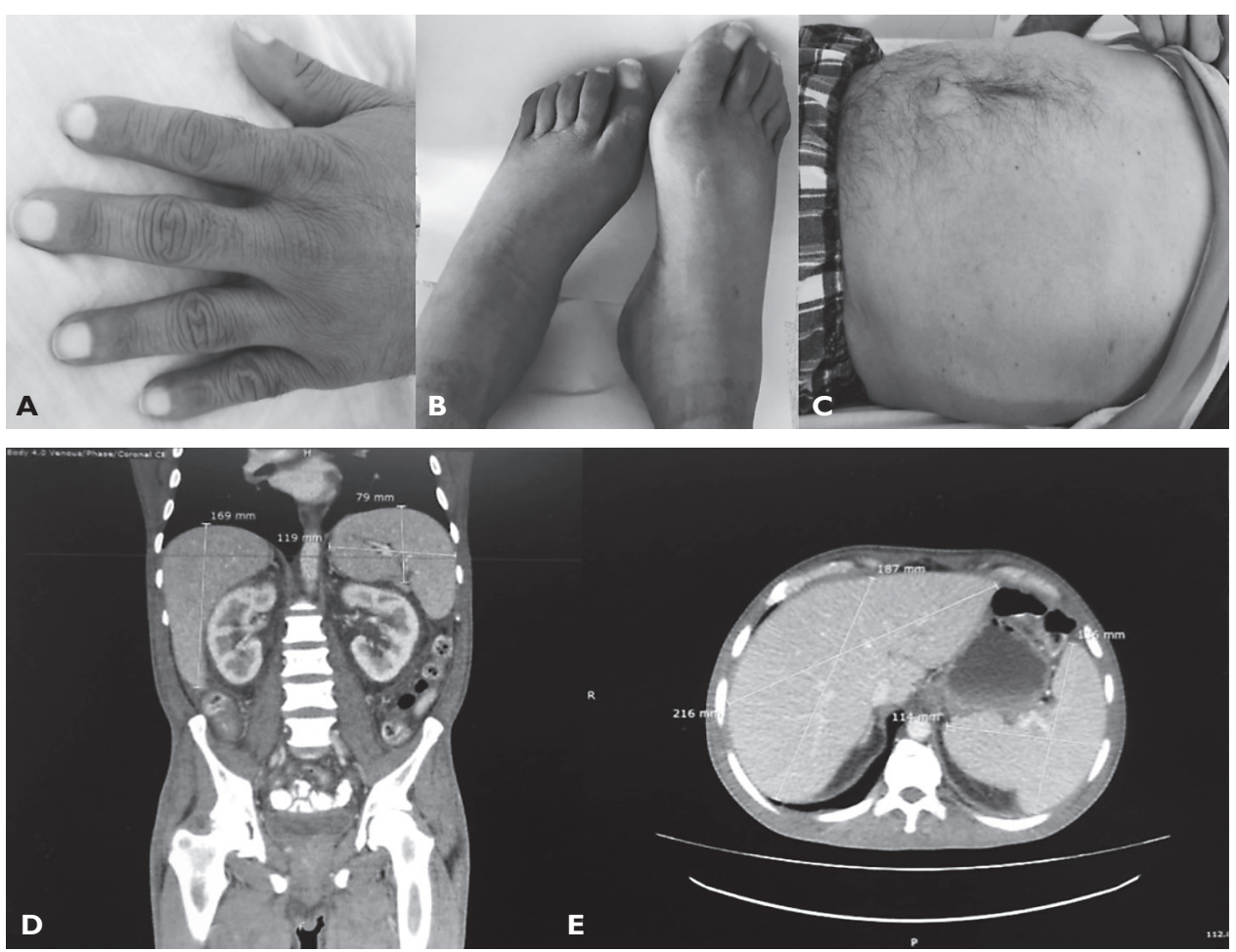

Figure 1 - Semiologic findings of the patient compatible with POEMS syndrome. A) leukonychia; B) edema; C) ascites; D) and E) hepatosplenomegaly.

Everything described previously led to a bone marrow biopsy which resulted in megakaryocytic hyperplasia, dysmegakaryopoietic changes, and increased plasmacytes.

POEMS syndrome became a more likely diagnostic possibility once two major criteria and four minor criteria (organomegaly, endocrinopathy, skin changes and volume overload) were met. Therefore, long bone X-rays were taken which ruled out the presence of lithic or sclerotic lesions. Finally, the diagnosis was confirmed thanks to a VEGF of $433.9 \mathrm{pg} / \mathrm{ml}$ (normal: $128.9 \mathrm{pg} / \mathrm{ml}$ ). The patient was then referred to a level of greater complexity for a hematology consult and to decide on an autologous hematopoietic cell transplant.

\section{Discussion}

POEMS syndrome is a proliferative monoclonal plasma cell disorder that leads to a systemic inflammatory response mediated by the presence of cytokines (Gherardi et al., 1996; Michizono et al., 2001). VEGF is an angiogenic cytokine that is found significantly elevated in these cases, and therefore it is a strategic biomarker when 


\section{Table 2 - Diagnostic criteria for POEMS syndrome}

\begin{tabular}{ll}
\hline $\begin{array}{l}\text { Mandatory major } \\
\text { criteria (both) }\end{array}$ & $\begin{array}{l}\text { Polyneuropathy } \\
\text { Monoclonal plasma cell-proliferative disorder }\end{array}$ \\
\hline $\begin{array}{l}\text { Major criteria } \\
\text { (at least one) }\end{array}$ & $\begin{array}{l}\text { Castleman's disease } \\
\text { Sclerotic or lytic bone lesions } \\
\text { Vascular endothelial growth factor elevation }\end{array}$ \\
\hline & $\begin{array}{l}\text { Organomegaly (splenomegaly, hepatomegaly, or lymphadenopathy) } \\
\text { Extravascular volume overload (edema, pleural effusions, or ascites) } \\
\text { Endocrinopathy (adrenal, thyroid, pituitary, gonadal, parathyroid } \\
\text { Minor criteria }\end{array}$ \\
(at least one) & $\begin{array}{l}\text { Changes in skin: hypertrichosis, acrocyanosis, leukonychia } \\
\text { Papilledema } \\
\text { Thrombocytosis, polycythemia }\end{array}$ \\
\hline
\end{tabular}

making this diagnosis and during the follow-up (Watanabe et al., 1996; D'Souza et al., 2011; Keddie et al., 2018). However, the proper, official diagnosis is made using the criteria established by Dispenzieri et al. in 2003 that include clinical, paraclinical and imaging findings (Table 2).

The characteristic plasma cell disorder includes the presence monoclonal proteins, also known as paraproteins, in plasma, serum and/or urine. These are composed from a single heavy chain ( $\mathrm{M}, \mathrm{G}$ or $\mathrm{A}$ ) and a single light chain (kappa or lambda). According to Vallat et al. (1996), the paraproteins usually associated to polyneuropathies tend to be IgM and kappa, which varies from a key aspect of POEMS, given that the latter tends to be associated to IgA or IgG and lambda light chains in $95 \%$ of cases, including the above-mentioned case (Vallat et al., 1996; Dispenzieri et al., 2003). In order to achieve a better test sensitivity, these proteins should be found through protein electrophoresis, immunofixation, and light chain analysis in both serum and urine samples. This should be taken in account, given that if only protein electrophoresis is done, there can be up to $30 \%$ false negatives (Dispenzieri et al., 2003).

Once confirmed, a bone marrow biopsy should be done in order to properly guide treatment. Approximately $66 \%$ of POEMS syndrome patients' biopsies will show a malignant cellular clone with a high rate of cellular abnormalities limited to expressing lambda light chains (Dispenzieri et al., 2003; Dao et al., 2011; Keddie et al., 2018). The $33 \%$ of remaining biopsies that do not show these clones could point to a cellar disorder limited to solitary or multifocal plasmacytomas located in soft or bone tissues (Dao et al., 2011; Keddie et al., 2018). It should be noted that although in the case described no malignant clones or plasmacytomas were found in the bone marrow sample, their presence cannot be completely ruled out due to their extremely small size. 
Table 3 - POEMS syndrome diagnostic approach

\begin{tabular}{|c|c|c|}
\hline Characteristic & Diagnostic study & Typical abnormality \\
\hline \multirow{3}{*}{ Polyneuropathy } & $\begin{array}{l}\text { Nerve conduction/ } \\
\text { electromyography }\end{array}$ & $\begin{array}{l}\text { Axonal and demyelinating polyneuropathy, } \\
\text { more frequent demyelinating }\end{array}$ \\
\hline & Nerve biopsy & $\begin{array}{l}\text { Not necessary if diagnosis is clear with } \\
\text { elevated VEGF levels. } \\
\text { Axonal degeneration, diffuse myelinated } \\
\text { fiber loss, increased epineural blood } \\
\text { vessels }\end{array}$ \\
\hline & Cerebrospinal fluid* & $\begin{array}{l}\text { Albuminocytologic dissociation; normal } \\
\text { cell count; mild increase opening pressure; } \\
\text { not specific so not always necessary }\end{array}$ \\
\hline Organomegaly & $\begin{array}{l}\text { CT scan of chest/abdomen/ } \\
\text { pelvis and PET-CT }\end{array}$ & Lymph node, spleen, liver \\
\hline \multirow{6}{*}{ Endocrinopathy } & Adrenal: cortisol & Typically low \\
\hline & Thyroid: TSH, T4 & Hypothyroid or hyperthyroid \\
\hline & $\begin{array}{l}\text { Pituitary: LH, FSH, IGF-1, } \\
\text { ACTH, prolactin }\end{array}$ & Typically hypofunctioning \\
\hline & Gonadal: testosterone, oestradiol & Typically low \\
\hline & Parathyroid: PTH & \\
\hline & Pancreatic: HbA1c, glucose & Typically raised \\
\hline \multirow{3}{*}{$\begin{array}{l}\text { Monoclonal plasma } \\
\text { cell disorder }\end{array}$} & $\begin{array}{l}\text { Serum protein electrophoresis } \\
\text { Immunofixation } \\
\text { Serum free light chain analysis }\end{array}$ & IgG or IgA lambda monoclonal protein \\
\hline & $\begin{array}{l}\text { Urine protein electrophoresis/ } \\
\text { immunofixation }\end{array}$ & Bence Jones proteins \\
\hline & $\begin{array}{l}\text { Bone marrow biopsy } \\
\pm \text { targeted bone lesion biopsy }\end{array}$ & $\begin{array}{l}\text { Presence of plasma cells in } \\
\text { immunofixation, typically lambda light } \\
\text { chain restricted }\end{array}$ \\
\hline Skin & Clinical diagnosis & $\begin{array}{l}\text { Acrocyanosis, hypertrichosis, nail changes, } \\
\text { glomerular hemangiomas }\end{array}$ \\
\hline Papilledema & Ophthalmological assessment & \\
\hline $\begin{array}{l}\text { Extravascular volume } \\
\text { overload/cardiac } \\
\text { involvement }\end{array}$ & Echocardiogram* & $\begin{array}{l}\text { Reduction of let or right ventricular } \\
\text { ejection fraction, elevation of pulmonary } \\
\text { artery pressure; evidence of previous } \\
\text { ischemia }\end{array}$ \\
\hline $\begin{array}{l}\text { Sclerotic bone } \\
\text { lesions }\end{array}$ & $\begin{array}{l}\text { CT bone windows, } \\
\text { PET-CT imaging }\end{array}$ & Sclerotic lesions/mixed lytic with sclerotic \\
\hline Thrombocytosis & Full blood count & Increased platelets \\
\hline $\begin{array}{l}\text { Pulmonary } \\
\text { function }\end{array}$ & $\begin{array}{l}\text { Pulmonary function } \\
\text { tests* }\end{array}$ & $\begin{array}{l}\text { Pulmonary hypertension, restrictive } \\
\text { disease, respiratory muscle weakness, } \\
\text { reduced diffusion capacity }\end{array}$ \\
\hline
\end{tabular}

*not necessary for diagnosis, but useful; VEGF - vascular endothelial growth factor; CT - computed tomography; PET - positron emission tomography; TSH - thyroid-stimulating hormone; ACTH - adrenocorticotropic hormone; LH - luteinizing hormone; PTH - parathyroid hormone; IGF-1 - insulin like growth factor-1 
Due to the aforementioned, a CT or a positron emission tomography to assess the presence of lytic or bone sclerotic lesions should be taken. This is key, taking into account that a normal bone marrow biopsy could false lead to a missed or delayed diagnosis.

In what relates to the multisystemic findings, the endocrinopathy usually presents in around $65 \%$ of cases, more frequently as erectile dysfunction and gynecomastia in men, and as early menopause symptoms in women. Taking that into consideration, it is very interesting that our case presents an endocrinopathy as the adrenal insufficiency, which is a rarer disease. In regards to the organomegaly, only $50 \%$ of patients express it, and usually affecting the liver, spleen or lymphatics, as reflected in our patient's CT (Keddie et al., 2018). Lastly, multiple skin lesions have been described as frequent expression of POEMS including glomeruloid-like hemangiomas, reddish dome-shaped papules on the trunk and extremities, leukonychia and hypertrichosis (Keddie et al., 2018).

Though rare, it is a diagnosis that should be considered in patients with chronic, usually demyelinating, polyneuropathy of unclear origin who also present multisystemic findings. One of its main differential diagnosis is Demyelinating Chronic Inflammatory Polyneuropathy. Up to $60 \%$ of POEMS patients are initially diagnosed with said pathology, wrongly treated with immunomodulatory therapy, which would result ineffective and essentially just delay the actual diagnosis for a period of around 12 months (Nasu et al., 2012). Table 3 exhibits the diagnostic tools for a proper approach to POEMS syndrome.

As far as for treatment for POEMS, the use of monoclonal antibodies that block VEGF has been proved to be harmful to the patient, even fatal, which just goes to show that although a useful diagnostic biomarker, VEGF's pathophysiological role is still unclear (Keddie et al., 2018). The main therapeutic goal is to suppress monoclonal plasma cell proliferation. In cases with systemic affection (bone marrow, or 3 or more plasmacytomas), gold standard treatment includes autologous stem cell transplant and chemotherapy. In patients with localized affection (less than 2 plasmacytomas without bone marrow affectation) radiotherapy is recommended (Dispenzieri, 2017; Keddie et al., 2018).

We depicted a clinical case describing a patient with POEMS syndrome, which was diagnosed taking into account the expression of multisystemic findings along with his chronic neuropathy. This report highlights the significance of an adequate semiological evaluation and high diagnostic suspicion to achieve a timely detection of this pathology, looking to avoid clinical progression and unnecessary studies. In closing, opportune treatment plays a fundamental role in avoiding clinical deterioration, therefore emphasizing the importance of considering POEMS syndrome a differential diagnosis in patients presenting with chronic polyneuropathy and Demyelinating Chronic Inflammatory Polyneuropathy accompanied by other seemingly unrelated findings. 


\section{References}

D’Souza, A., Hayman, S. R., Buadi, F., Mauermann, M., Lacy, M. Q., Gertz, M. A., Kyle, R. A., Kumar, S., Greipp, P. R., Lust, J. A., Zeldenrust, S., Witzig, T. E., Raikumar, S. V., Dispinzeri, A. (2011) The utility of plasma vascular endothelial growth factor levels in the diagnosis and follow-up of patients with POEMS syndrome. Blood 118(17), 4663-4665.

Dao, L. N., Hanson, C. A., Dispenzieri, A., Morice, W. G., Kurtin, P. J., Hoyer, J. D. (2011) Bone marrow histopathology in POEMS syndrome: A distinctive combination of plasma cell, lymphoid, and myeloid findings in 87 patients. Blood 117(24), 6438-6444.

Dispenzieri, A. (2017) POEMS syndrome: 2017 update on diagnosis, risk stratification, and management. Am. J. Hematol. 92(8), 814-829.

Dispenzieri, A., Kyle, R. A., Lacy, M. Q., Rajkumar, S. V., Therneau, T. M., Larson, D. R., Greipp, P. R., Witzig, T. E., Basu, R., Suarez, G. A., Fonseca, R., Lust, J. A., Gertz, M. A. (2003) POEMS syndrome: Definitions and long-term outcome. Blood 101(7), 2496-2506.

Gherardi, R. K., Bélec, L., Soubrier, M., Malapert, D., Zuber, M., Viard, J. P., Intrator, L., Degos, J. D., Authier, F. J. (1996) Overproduction of proinflammatory cytokines imbalanced by their antagonists in POEMS syndrome. Blood 87(4), 1458-1465.

Keddie, S., D'sa, S., Foldes, D., Carr, A. S., Reilly, M. M., Lunn, M. P. T. (2018) POEMS neuropathy: Optimising diagnosis and management. Pract. Neurol. 18(4), 278-290.

Kuwabara, S., Dispenzieri, A., Arimura, K., Misawa, S., Nakaseko, C. (2012) Treatment for POEMS (polyneuropathy, organomegaly, endocrinopathy, M-protein, and skin changes) syndrome. Cochrane Database Syst. Rev. 2012(6), CD006828.

Michizono, K., Umehara, F., Hashiguchi, T., Arimura, K., Matsuura, E., Watanabe, O., Fujimoto, N., Okada, Y., Osame, M. (2001) Circulating levels of MMP-1, -2, -3, -9, and TIMP-1 are increased in POEMS syndrome. Neurology 56(6), 807-810.

Nasu, S., Misawa, S., Sekiguchi, Y., Shibuya, K., Kanai, K., Fujimaki, Y., Ohmori, S., Mitsuma, S., Koga, S., Kuwabara, S. (2012) Different neurological and physiological profiles in POEMS syndrome and chronic inflammatory demyelinating polyneuropathy. J. Neurol. Neurosurg. Psychiatry 83(5), 476-479.

Plaza, C., Arquero, R., García-Raso, A., Llamas, P. (2016) Diagnóstico de síndrome de POEMS tras neuropatía de larga evolución. Neurologia (Barcelona, Spain) 34(4), 272-274.

Suichi, T., Misawa, S., Beppu, M., Takahashi, S. (2019) Prevalence, clinical profiles, and prognosis of POEMS syndrome in Japanese nationwide survey. Neurology 93(10), 975-984.

Vallat, J. M., Jauberteau, M. O., Bordessoule, D., Yardin, C., Preux, P. M., Couratier, P. (1996) Link between peripheral neuropathy and monoclonal dysglobulinemia: A study of 66 cases. J. Neurol. Sci. 137(2), 124-130.

Watanabe, O., Arimura, K., Kitajima, I., Osame, M., Maruyama, I. (1996) Greatly raised vascular endothelial growth factor (VEGF) in POEMS syndrome. Lancet 347(9002), 702. 